\title{
Análisis sobre la implantación del singular modelo de Cartas de Servicios en Cataluña
}

\section{Analysis on the implementation of the unique model of Services Cards in Catalonia}

\author{
María del Mar Caraza Cristín \\ Universidad de Sevilla \\ mcaraza@us.es
}

\section{NOTA BIOGRÁFICA}

Titulada Superior de la Junta de Andalucía y profesora asociada doctora del Departamento de Derecho Administrativo de la Universidad de Sevilla. Es autora de diversos artículos sobre: el acto administrativo; los procedimientos de revisión de oficio; la responsabilidad patrimonial administrativa; las fundaciones; y la vivienda protegida en Andalucía (relativos a los derechos de tanteo y retracto, el régimen de la descalificación, los planes municipales de vivienda y suelo, los registros públicos municipales de demandantes de vivienda protegida y a su función social). Asimismo, tiene publicadas las siguientes monografías: La Cámara de Cuentas de Andalucía y el Procedimiento Administrativo Común, Civitas (2002), y La responsabilidad patrimonial de la Administración y su relación con los estándares de calidad de los servicios públicos, INAP (2016).

\section{RESUMEN}

En Cataluña, las Cartas de Servicios cuentan con una regulación singular, hasta el momento única. La Ley de Transparencia, Acceso a la Información Pública y Buen Gobierno de esta Comunidad las ha dotado de carácter reglamentario y efectos jurídicos vinculantes. Han pasado de ser soft law a hard law. Y este hecho tiene también importantes consecuencias en el campo de la responsabilidad patrimonial de la Administración. Dos años después de la entrada en vigor de la citada Ley, es el momento de analizar cuál ha sido la implantación real de esta novedosa regulación y sacar conclusiones.

\section{PALABRAS CLAVE}

Cartas de Servicios, compromisos de calidad, estándar, buena administración y responsabilidad.

\begin{abstract}
In Catalonia, services cards have an unique regulation, so far singular. The law on transparency, access to public information and corporate governance of this community has given them statutory and binding legal effects. They have gone from soft to hard law. And this fact has important consequences in the field of administration's patrimonial responsibility. Two years after the entry into force of this law, it is time to analyze what has been the actual implementation of this new regulation and draw conclusions.
\end{abstract}

\section{KEYWORDS}

Services Cards, quality commitments, standard, good governance and responsibility. 
REALA. Nueva Época - N. ${ }^{9}$, Abril 2018 - ISSN: 1989-8975 - DOI: 10.24965/reala.v0i9.10443 - [Págs. 41-59]

Análisis sobre la implantación del singular modelo de Cartas de Servicios en Cataluña

María del Mar Caraza Cristín

\begin{abstract}
SUMARIO
I. INTRODUCCIÓN. II. MARCO NORMATIVO DE LAS CARTAS DE SERVICIOS 1. CONCEPTO. 2. CLASES. 3. CONTENIDO. 4. LOS COMPROMISOS DE CALIDAD. 5. CONSECUENCIAS QUE GENERA SU INCUMPLIMIENTO. 6. SEGUIMIENTO Y EVALUACIÓN. III. LA PIONERA REGULACIÓN DE LAS CARTAS DE SERVICIOS EN CATALUÑA. 1. CONTEXTO NORMATIVO. 2. SINGULARIDADES. 2.1. ELABORACIÓN OBLIGATORIA. 2.2. CARÁCTER REGLAMENTARIO. 2.3. EFECTOS VINCULANTES. IV. SITUACIÓN DE LAS CARTAS DE SERVICIOS TRAS LA LEY 19/2014. 1. INFORMES DEL SINDIC DE GREUGES. 2. PROCEDIMIENTO PARA LA ELABORACIÓN DE LAS CARTAS. 3. ANÁLISIS DE LAS CARTAS DE SERVICIOS APROBADAS O REVISADAS. 4. PLAZO PARA LA APROBACIÓN DE LAS NUEVAS CARTAS. V. CONSECUENCIAS DEL INCUMPLIMIENTO DE LOS ESTÁNDARES DE CALIDAD EN EL PLANO DE LA RESPONSABILIDAD PATRIMONIAL DE LAADMINISTRACIÓN. 1. REFERENCIAA LANUEVA REGULACIÓN DE LA RESPONSABILIDAD PATRIMONIAL. 2. PRESUNCIONES DERIVADAS DEL CUMPLIMIENTO DE LOS ESTÁNDARES. VI. CONCLUSIONES.
\end{abstract}

\title{
I. INTRODUCCIÓN
}

En las últimas décadas la filosofía de la calidad ha ido poco a poco asentándose en el mundo de lo público. Una clara consecuencia jurídica ha sido la plasmación en diversos textos normativos del derecho de los ciudadanos a disfrutar de unos servicios públicos de calidad, como parte del derecho fundamental a la buena administración, regulado en el artículo 41 de la Carta de Derechos Fundamentales de la Unión Europea1.

Implícitamente este derecho también se contempla en algunos preceptos de la Constitución española (arts. 3, 9.3, 103, 105 y 106.2), así como en los nuevos Estatutos de Autonomía (Cataluña, Castilla y León, Islas Baleares, Andalucía y Aragón) y en normas tanto estatales como autonómicas, en especial, las dedicadas a la Transparencia, la Buena Administración y el Buen Gobierno².

Uno de los instrumentos que más virtualidad presentan para la consecución del derecho a la buena administración son las Cartas de Servicios. A través de estos documentos de carácter informativo, normas de soft law no incardinadas en el sistema oficial de fuentes del Derecho, las Administraciones establecen voluntariamente estándares que se comprometen a cumplir para ofrecer a la ciudadanía servicios públicos de calidad.

No obstante, la Ley 19/2014, de 29 de diciembre, de Transparencia, Acceso a la Información Pública y Buen Gobierno de la Comunidad Autónoma de Cataluña (LTAIPBGC) ha supuesto un cambio radical del planteamiento hasta el momento mantenido respecto a la figura de las Cartas de Servicios. Ha impuesto la obligatoriedad de su elaboración y les ha reconocido carácter reglamentario y efectos vinculantes.

Han pasado dos años desde la entrada en vigor de la LTAIPBGC y es el momento de hacer una primera valoración de cuál ha sido la verdadera puesta en práctica del nuevo modelo de Cartas de Servicios por parte de la Generalidad de Cataluña y de las Administraciones locales de esta Comunidad.

\section{MARCO NORMATIVO DE LAS CARTAS DE SERVICIOS}

Antes de abordar la regulación que hace el legislador catalán de las Cartas de Servicios, conviene hacer referencia al marco normativo general que es de aplicación a esta figura en el Estado y en las demás Comu-

\footnotetext{
1 Sobre el contenido de este derecho y su regulación en la normativa europea vid. Jesús Ángel FUENTETAJA, “El derecho a la buena administración en la Carta de los Derechos Fundamentales de la Unión Europea", RDUE, núm. 15 (2008), págs. 137-154 y Javier GUILLEM CARRAU, "El avance del derecho a la buena administración en el Tratado de Lisboa", RDUE núm. 19 (2010), págs. 31-70. Por otra parte, véase el estudio de Julio PONCE SOLÉ que recoge la jurisprudencia del Tribunal de Justicia de la Unión Europea y del Tribunal Europeo de Derechos Humanos, así como del Tribunal Supremo y Tribunales Superiores de Justicias de las Comunidades Autónomas, recaída en los últimos años y que aplica este derecho y delimita el alcance de su contenido, "Los jueces, el derecho a una buena administración y las leyes de transparencia y buen gobierno", publicado el 19 de enero de 2017 en http://laadministracionaldia.inap.es/noticia.asp?id=1507021.

2 En contra de esta tendencia, Ilama la atención que en el art. 13 de la Ley 39/2015 no se haya recogido el derecho de los ciudadanos a la calidad de los servicios públicos, que sí venía regulado en la Ley 11/2007, ni expresamente el derecho a la buena administración, como sí recoge el art. 22 de la Ley de Régimen Jurídico y de Procedimiento de las Administraciones Públicas de Cataluña. Vid. Isaac MARTÍN DELGADO, "La reforma de la Administración Electrónica: una panorámica general del impacto de la nueva Ley de Procedimiento Administrativo Común en las relaciones de los ciudadanos con la Administración Pública", y Tomás CANO CAMPOS, "Derechos y deberes de las personas en sus relaciones con las Administraciones Públicas: la vuelta del «administrado»", en Innovaciones en el Procedimiento Administrativo Común y el Régimen Jurídico del Sector Público, ob. dir. por Francisco LÓPEZ MENUDO, EUS, Sevilla, 2016, pág. 54 y pág. 122, respectivamente.
} 
nidades Autónomas. A nivel estatal, es el Real Decreto 951/2005, de 29 de julio, por el que se establece el Marco General para la Mejora de la Calidad de la Administración General del Estado, la norma de referencia; por su parte, a nivel autonómico, hay algunas Comunidades Autónomas, como Galicia, Aragón, Castilla-La Mancha y Cataluña, que regulan esta figura en Leyes - dedicadas a la transparencia y a la buena administración o a la calidad de los servicios públicos-, mientras que el resto lo hace por Decreto u Orden.

Como consecuencia de este panorama normativo, se aprecia una divergencia respecto al ámbito subjetivo de aplicación de esta figura, su contenido mínimo, forma de aprobación y, desde la aprobación de la LTAIPBGC, una radical diferencia respecto a la obligatoriedad de su elaboración, naturaleza y efectos jurídicos.

\section{Concepto}

El artículo 8.1 del RD 951/2005 define a las Cartas de Servicios como aquellos «documentos que constituyen el instrumento a través del cual los órganos, organismos y entidades de la Administración General del Estado informan a los ciudadanos y usuarios sobre los servicios que tienen encomendados, sobre los derechos que les asisten en relación con aquellos y sobre los compromisos de calidad en su prestación». Por su parte, el apartado segundo contempla la potestad discrecional de los órganos, organismos y entidades de la Administración General del Estado para elaborar Cartas relativas al conjunto de los servicios que gestionan y Cartas que tengan por objeto un servicio específico.

La Carta de Compromisos con la Calidad de las Administraciones Públicas Españolas, publicada por el Ministerio de Administraciones Públicas y la Agencia de Evaluación de la Calidad de las Políticas Públicas y la Calidad de los Servicios (AEVAL ${ }^{3}$ ) en 2009, establece en su compromiso octavo el deber de las Administraciones Públicas españolas, en sus tres niveles territoriales, de elaborar y difundir Cartas de Servicios que recojan los compromisos de mayor interés para la ciudadanía, los estándares de calidad e indicadores asociados a los mismos.

Como desarrollo del referido compromiso, la AEVAL edita en 2015 el documento Marco Común sobre las Cartas de Servicios en las Administraciones Públicas Españolas; en él ofrece la siguiente definición de las Cartas de Servicios, como instrumentos para la mejora continua de los servicios:

«documentos por medio de los cuales las organizaciones públicas informan sobre los compromisos de calidad de los servicios que gestionan y prestan, en respuesta a las necesidades y expectativas de los ciudadanos y usuarios y a la demanda de transparencia en la actividad pública».

Desde esta óptica, las Cartas de Servicios son documentos incardinados en el concepto de soft law. Un amplio porcentaje de ellas son de elaboración voluntaria para sus organizaciones y, cuando su elaboración es obligatoria, no se contempla ninguna medida ante el incumplimiento de tal obligación ${ }^{4}$.

\section{Clases}

Las Cartas de Servicios se pueden clasificar según múltiples criterios y, en función de los mismos, puede hablarse de: Cartas individualizadas por servicios o agrupadas (tal y como se contempla en el art. 8.2 del RD 951/2005 y en el art. 26.4 de la Ley 26/2010, de 3 de agosto, de Régimen Jurídico y de Procedimiento de las Administraciones Públicas de Cataluña); Cartas de Servicios tradicionales/convencionales o Cartas de Servicios electrónicos (estas últimas previstas en el art. 13 del RD 951/2005); Cartas de Servicios externas, internas o mixtas, según se dirijan a los ciudadanos, a los empleados públicos o a ambos; Cartas

\footnotetext{
${ }^{3}$ De conformidad con lo dispuesto en la Disposición adicional novena del Real Decreto 769/2017, de 28 de julio, por el que se desarrolla la estructura orgánica básica del Ministerio de Hacienda y Función Pública y se modifica el Real Decreto 424/2016, de 11 de noviembre, por el que se establece la estructura orgánica básica de los departamentos ministeriales, se acuerda la disolución de la Agencia Española de Evaluación de Políticas Públicas, según lo dispuesto en el artículo 96.1, g) de la Ley 40/2015, de 1 de octubre, cuyas funciones serán asumidas por la Secretaría de Estado de Función Pública.

${ }^{4}$ El documento Marco Común sobre las Cartas de Servicios en las Administraciones Públicas Españolas muestra que en el $64,70 \%$ los programas de Cartas de Servicios tienen carácter voluntario para las Administraciones Públicas, y sólo es obligatoria su elaboración en un $35,30 \%$, sin que se establezcan consecuencias en caso de incumplimiento (vid. pág. 19). El citado documento, aprobado por la Red Interadministrativa de Calidad en los Servicios Públicos en su reunión del día 25 de noviembre de 2014, puede consultarse en $h$ ttp://www.aeval.es.
} 
REALA. Nueva Época - N. ${ }^{9}$, Abril 2018 - ISSN: 1989-8975 - DOI: 10.24965/reala.v0i9.10443 - [Págs. 41-59]

Análisis sobre la implantación del singular modelo de Cartas de Servicios en Cataluña

María del Mar Caraza Cristín

interdepartamentales o interadministrativas (previstas en el art. 8.3 del RD 951/2005); Cartas de Servicios certificadas, etc.

\section{Contenido}

El art. 9 del RD 951/2005 describe el contenido que ha de tener una Carta de Servicios, diferenciando, por un lado, una regulación de carácter general y, por otro, los compromisos de calidad.

El contenido general viene predeterminado por normas legales o reglamentarias. En él se establecen las condiciones que deberá cumplir el servicio. Así, conforman este contenido: los datos relativos a la identificación del órgano u organismo y sus fines; los principales servicios que presta; los derechos concretos de los ciudadanos y usuarios respecto a esos servicios; las fórmulas de participación o colaboración de los usuarios en la mejora de los servicios; una relación sucinta y actualizada de la normativa reguladora de las principales prestaciones y servicios; y el acceso al sistema de quejas y sugerencias regulado en el Capítulo IV del RD 951/2005.

Por su parte, los denominados "compromisos de calidad» son obligaciones que voluntaria y libremente asume el prestador del servicio. Por esta razón, el cumplimiento de tales obligaciones no es vinculante para el ente administrativo prestador del servicio, empero, no puede obviarse que el propósito de explicitar dichas obligaciones y compromisos de calidad en las Cartas de Servicios no puede ser otro que el de llevarlos a efecto y que cuando se incumple se genera una gran insatisfacción en el usuario.

Es el contenido descrito, la regulación de los compromisos de calidad, el rasgo que distingue precisamente a las Cartas de Servicios de otras figuras con las que pueden guardar algunas semejanzas, como las Cartas de derechos ${ }^{5}$, las Carteras de Servicios ${ }^{6}$ o los Catálogos de Servicios ${ }^{7}$.

\section{Los compromisos de calidad}

Como hemos dicho, los compromisos de calidad son el elemento clave que diferencia a las Cartas de Servicios de otros documentos meramente informativos. De acuerdo con lo dispuesto en el art. 9.b) del RD 951/2005, los compromisos de calidad deben incluir:

"1. ${ }^{\circ}$ Niveles o estándares de calidad que se ofrecen y, en todo caso:

- Plazos previstos para la tramitación de los procedimientos, así como, en su caso, para la prestación de los servicios.

- Mecanismos de información y comunicación disponibles, ya sea general o personalizada.

- Horarios, lugares y canales de atención al público.

2. ${ }^{\circ}$ Medidas que aseguren la igualdad de género, que faciliten el acceso al servicio y que mejoren las condiciones de la prestación.

\footnotetext{
5 Póngase el caso de la Carta de Ciudadanía aprobada por el Ayuntamiento de Barcelona en 2015. Se trata de un texto que simplemente reproduce un gran número de derechos y deberes de los ciudadanos ya reconocidos en la Declaración Universal de Derechos Humanos, las Convenciones de los Derechos del Niño y de las Personas con Discapacidad, la Constitución, el Estatuto de Autonomía de Cataluña y otras Cartas y leyes. No contiene ningún compromiso nuevo por parte de la Administración, ni se establecen estándares de calidad para mejorar los servicios públicos existentes.

${ }^{6}$ Por ejemplo, la Cartera de Servicios Sociales 2010-2011 de Cataluña, aprobada por Decreto 142/2010, de 11 de octubre, es el instrumento que se aprueba por el Gobierno en desarrollo de la Ley 12/2007, de 11 de octubre, de Servicios Sociales de Cataluña, con una vigencia de cuatro años, revisable cada dos, por medio del cual se determina el conjunto de prestaciones de servicios, económicas y tecnológicas, de la Red de Servicios Sociales de Atención Pública. La Cartera define para cada prestación: la garantía; la descripción; el objeto; las funciones; la población destinataria; el establecimiento o el equipo de personal que la ha de gestionar; los perfiles y las ratios de profesionales del equipo; los criterios de acceso, los costes de referencia, módulo social o copago para las prestaciones no gratuitas; y los estándares de calidad, éstos últimos remitidos en su determinación a lo que fije el Plan de Calidad contemplado en la Ley de Servicios Sociales o a los que establezca el Departamento de Salud o de Acción Social y Ciudadanía. Las prestaciones garantizadas en la Cartera son exigibles como derechos subjetivos.

7 Por ejemplo, el Catálogo de Servicios de las oficinas de la vivienda del Ayuntamiento de Barcelona ofrece información sobre los servicios que prestan estas oficinas, pero no contempla compromisos de calidad, vid. http://habitatge.barcelona/es/red-de-oficinas/ catalogo-servicios. O el Catálogo de Servicios de Formación 2014 de la Dirección de Servicios de Formación de la Diputación Provincial de Barcelona, que recoge todos aquellos servicios de consultoría, asesoramiento y asistencia técnica que la Diputación presta a los municipios de su provincia, en función de la población de los mismos, vid. https:/www.diba.cat/es/web/formacio/cataleg-de-serveis.
} 
3. ${ }^{\circ}$ Sistemas normalizados de gestión de la calidad, medio ambiente y prevención de riesgos laborales con los que, en su caso, cuente la organización.

4. Indicadores utilizados para la evaluación de la calidad y específicamente para el seguimiento de los compromisos».

Entre las características que han de reunir los compromisos de calidad destacan: estar referidos a aspectos que sean relevantes en la percepción de la calidad del servicio para el ciudadano; ser comprensibles por los ciudadanos gracias a un lenguaje claro y sencillo; estar formulados de forma concreta y precisa, no dando lugar a interpretaciones diversas; que puedan ser invocables por los usuarios ante la organización; que sean cuantificables y medibles; pocos; y que vayan más allá de las obligaciones legales reguladas en la norma ${ }^{8}$.

Ni que decir tiene la importancia de la tarea de fijación de los estándares e indicadores por parte de cada Administración. El estándar sería el valor que sirve de referencia para medir la evolución de un determinado indicador ${ }^{9} \mathrm{y}$, a su vez, representa el nivel que, en relación con un objetivo, pretende conseguir una organización en un periodo de tiempo determinado.

Para el cálculo de los estándares, la organización puede partir tanto de datos teóricos como estadísticos sobre los factores que sean determinantes del servicio en cuestión, o puede acudir a datos y referencias existentes de otras organizaciones, ya pertenezcan a la misma entidad o a otras organizaciones, públicas o privadas, nacionales o extranjeras.

Comparando los resultados de los indicadores con los estándares se consigue evaluar el comportamiento de la entidad, mostrando hacia dónde se debe focalizar el análisis de las desviaciones.

En función de la organización, del servicio, el equipo de trabajo encargado de elaborar la Carta deberá determinar cuáles vayan a ser los indicadores para medir la evolución y el grado de cumplimiento de los resultados finales de un proyecto en relación con los objetivos prefijados. Entre las condiciones que deben reunir los indicadores destacan las siguientes: relevancia; capacidad para determinar pequeños cambios; utilidad; precisión; pertinencia; accesibilidad; objetividad; y periodicidad.

En definitiva, es importante verificar que el indicador mide lo que afirma que mide, que es comprendido por todas las personas de la organización, quienes deben tener claros la definición del indicador, la periodicidad de su medición, el responsable, el objetivo que mide y el sistema o método utilizado para su medición. Sólo así se podrá llegar a alcanzar y cumplir con el nivel que se haya fijado la organización respecto a cada uno de sus objetivos.

\section{Consecuencias que genera su incumplimiento}

Los incumplimientos de los compromisos de calidad recogidos en las Cartas de Servicios no siempre son objeto de una queja o reclamación por parte del usuario del servicio. Para los casos en los que el usuario sí ha manifestado ante la organización expresamente su queja, normalmente a través de «Buzones de Quejas y Sugerencias», las Cartas suelen contemplar como medidas de subsanación o compensación las siguientes: petición de disculpas; explicación de cuáles hayan sido las circunstancias que provocaron el incumplimiento en cuestión; comunicación de las medidas adoptadas para evitar que se vuelva a producir dicho incumplimiento; reparación del daño o perjuicio causados; y compensación o resarcimiento económico o de otra índole.

Partiendo de que el contenido de la Carta de Servicios es de carácter informativo y carece de efectos jurídicos vinculantes, el incumplimiento de los compromisos de calidad acordados no genera responsabilidad patrimonial de la Administración. Es más, la AEVAL recomienda en el documento Marco Común sobre las Cartas de Servicios en las Administraciones Públicas Españolas que expresamente la propia Carta de Servicios explicite este último extremo ${ }^{10}$.

\section{Seguimiento y evaluación}

Tan importante como la correcta fijación de los estándares e indicadores es realizar por parte de la Administración las tareas de seguimiento y evaluación, consistentes en comprobar, a través de un sistema de

\footnotetext{
${ }^{8}$ Vid. Marco Común sobre las Cartas de Servicios en las Administraciones Públicas Españolas, págs. 32-34.

9 Vid. el "Glosario de términos" de la Guía de Evaluación del Modelo de EVAM de 2009.

10 Vid. nota a pie núm. 3 de la pág. 34 del citado documento. Como ejemplo vid. la Carta de Servicios Electrónicos del Instituto Nacional de Administración Pública de 2015 (periodo de vigencia 2015-2018).
} 
gestión de procesos y mediante un Plan de Seguimiento, si se alcanzan o no los compromisos de calidad fijados. En el caso de que no se alcancen, procede una actualización de los mismos; para ello, es necesario que previamente se tengan definidas cuáles son las circunstancias no sustanciales que provocan la actualización de la Carta de Servicios (tales como adaptación a modificaciones organizativas, cambios normativos, o la aparición de nuevas necesidades y expectativas de los usuarios), así como los mecanismos a seguir. Mas, si se tratara de cambios sustanciales en el contenido de la Carta, la solución sería la aprobación de una nueva.

La evaluación de la Carta puede ser interna, realizada por el órgano o unidad que tenga atribuida esta competencia dentro de la organización, o por un órgano o entidad externa, independiente. La AEVAL ${ }^{11}$ recomienda que cada 3 ó 4 años toda Carta de Servicios sea evaluada por un órgano externo que certifique, entre otros extremos, el grado de cumplimiento de los compromisos y estándares fijados para, con base en dicho resultado, mantener la vigencia de la Carta, proceder a su modificación o dejarla sin efecto.

\section{LA PIONERA REGULACIÓN DE LAS CARTAS DE SERVICIOS EN CATALUÑA}

\section{Contexto normativo}

El Estatuto de Autonomía de Cataluña regula en el art. 30 el derecho a la buena administración y, concretamente, el apartado tercero dice que corresponde a las leyes «determinar los casos en que las Administraciones públicas de Cataluña y los servicios públicos que de ellas dependen han de adoptar una Carta de derechos de los usuarios y de obligaciones de los prestadores», lo cual hizo, en primer lugar, la Ley 26/2010, de 3 de agosto, de Régimen Jurídico y Procedimiento de las Administraciones públicas de Cataluña (LRJPAPC) y, con posterioridad, la LTAIPBGC.

El art. 23 LRJPAPC, tras su modificación por el art. 18 de la Ley 16/2015, de 21 de julio, de Simplificación de la Actividad Administrativa de la Administración de la Generalidad y de los Gobiernos Locales y de Impulso de la Actividad Económica, establece la obligatoriedad de elaborar Cartas de Servicios por parte de las Administraciones Públicas catalanas.

Por su parte, el art. 58 de la LTAIPBGC contempla el derecho al acceso y uso de unos servicios públicos de calidad y el art. 59 LTAIPBGC regula el contenido de las Cartas de Servicios de las Administraciones Públicas catalanas y, de forma totalmente novedosa en el panorama normativo, expresamente les reconoce, como expondremos a continuación, naturaleza reglamentaria y efectos jurídicos vinculantes.

\section{Singularidades}

El artículo 59.1 LTAIPBGC establece el deber de la Administración de garantizar que los servicios de su competencia se prestan en unas «condiciones mínimas y razonables de calidad», y ello incluye la elaboración de Cartas de Servicios en el marco regulador de los «servicios públicos básicos». En este punto, sorprende la inclusión del adjetivo «básicos», puesto que, atendiendo a una interpretación literal del precepto, ello supondría dejar al margen a los servicios públicos de interés general, económico o no.

Con relación al contenido mínimo, obligatorio, que han de incluir las Cartas de Servicios, el citado art. 59.1 indica lo siguiente:

«a) La organización y la forma gestión del servicio.

b) La identificación de los responsables de la gestión.

c) Los estándares mínimos de calidad del servicio desglosados, en su caso, por categorías de prestaciones, y los indicadores e instrumentos para evaluar su aplicación.

d) Las condiciones de acceso.

e) Los derechos y deberes de los usuarios.

f) El régimen económico aplicable, con indicación de las tasas y los precios públicos que sean de aplicación, en su caso.

g) Las vías de reclamación utilizables.

h) Las vías utilizables para que los usuarios puedan obtener información y orientación con relación al servicio público.»

11 Vid. Marco Común sobre las Cartas de Servicios en las Administraciones Públicas Españolas, págs. 60-67. 
Si comparamos este contenido mínimo con el regulado en el art. 9 del RD 951/2005, se aprecia que el art. 59.1 LTAIPBGC incluye nuevos extremos relativos a: la determinación de cuál sea «la forma de gestión del servicio» de que se trate (gestión directa o indirecta); y el «régimen económico aplicable», con indicación, en su caso, de las tasas y precios públicos correspondientes. Con relación a los estándares de calidad del servicio llama la atención que el art. 59.1 expresamente habla de los estándares «mínimos» y deja fuera del contenido mínimo de la Carta otros aspectos que, a nuestro entender, deberían explicitarse, tales como el marco normativo de referencia, los servicios que se ofrecen, la fecha de inicio y el periodo de vigencia de la Carta, extremos éstos que, por ejemplo, sí se citan en el art. 38 de la Ley 4/2016, de 15 de diciembre, de Transparencia y Buen Gobierno de Castilla-La Mancha.

En el caso de las Cartas de Servicios objeto de nuestro estudio, el respeto a su contenido mínimo cobra mayor fuerza, dada su naturaleza de norma reglamentaria, puesto que su incumplimiento podría ser objeto de recurso.

\subsection{Elaboración obligatoria}

El art. 23.3 LRJPAPC establece que las Administraciones Públicas deben tener Cartas de Servicios a disposición de los ciudadanos, empresas y profesionales, como instrumento para la mejora de la calidad de los servicios, en los términos establecidos en la normativa vigente, en este caso, la LTAIPBGC.

El apartado cuarto del artículo 23 de la LRJPAPC, añadido por el art. 18 de la Ley 16/2015, establece que «Las unidades orgánicas de la Administración de la Generalidad con rango mínimo de Dirección General deberán disponer de una Carta de Servicios por cada uno de los servicios finalistas que presten».

A la hora de impulsar la elaboración de una Carta de Servicios y la determinación de su contenido, los políticos y autoridades competentes deben tomar sus decisiones con base en el trabajo de análisis realizado por los técnicos, que ha de partir de cuáles son los estándares que la Administración venía cumpliendo, los que actualmente cumple, así como los que cumplen otras Administraciones homólogas ${ }^{12}$. Es importante que la Carta de Servicios que se apruebe responda a ese previo estudio, y se base en estándares objetivos, realistas, que el órgano u Administración en cuestión pueda asumir en función de su dimensión, recursos materiales, personales, etc., y atendiendo siempre a las metas y objetivos a alcanzar, y todo ello en un proceso de mejora continua.

En Cataluña, como hemos dicho, los estándares y compromisos que se expliciten en las Cartas de Servicios son de acatamiento obligatorio y su incumplimiento genera consecuencias jurídicas, pero ello no debe conllevar que los políticos que en este momento se encuentren al frente del órgano de gobierno, para evitar posibles responsabilidades en caso de incumplimientos, establezcan estándares de nivel bajo o insuficiente (en este caso, el cumplimiento de dichos estándares podría no ser tenido en cuenta a la hora de determinar responsabilidades, como luego expondremos).

Por otro lado, con respecto a los políticos que se encuentren en la oposición (pensemos en los concejales que conforman el Pleno de un Ayuntamiento), no le es dable instar la fijación de unos estándares de calidad muy elevados, distantes de los análisis y estudios técnicos de las circunstancias concretas del servicio en cuestión, pues también sobre ellos recae la responsabilidad de realizar propuestas razonables, y no irreales y de las cuales solo pueda derivarse, ante su seguro incumplimiento, responsabilidad para la Administración. Esta reflexión es extensible a las propuestas que pueda realizar la ciudadanía.

\subsection{Carácter reglamentario}

El art. 59 LTAIPBGC reconoce expresamente la naturaleza reglamentaria de las Cartas de Servicios en Cataluña, en sentido contrario a lo que se dispone en la normativa estatal o de otras Comunidades Autónomas $^{13}$.

12 La elaboración de la Carta de Servicios tendría que ser llevada a cabo por un grupo de trabajo multidisciplinar. A estos efectos, resulta útil conocer el diagrama básico del proceso de elaboración de los compromisos de calidad que propone la AEVAL en el documento Marco Común sobre las Cartas de Servicios en las Administraciones Públicas Españolas, págs. 43-47.

13 Como el art. 20.2 de la Ley 5/2013, de 20 de junio, de Calidad de los Servicios Públicos de la Administración de la Comunidad Autónoma de Aragón y el art. 42.2 de la Ley 1/2015, de 1 de abril, de Garantía de Calidad de los Servicios Públicos y de la Buena Administración de Galicia, que expresamente niegan el carácter de disposiciones normativas de las Cartas de Servicios y que surtan efectos jurídicos vinculantes. 
Al tratarse, pues, de una norma reglamentaria, por aplicación tanto de la normativa común contenida en la Ley 39/2015, de 1 de octubre, del Procedimiento Administrativo Común de las Administraciones Públicas (LPACAP) como de las disposiciones contenidas en el Capítulo II de la LTAIPBGC, es necesario permitir a la ciudadanía conocer el proyecto normativo de Carta de Servicios que la Administración pretende tramitar para que pueda ejercer su derecho a participar en la elaboración de esta disposición normativa, mediante la presentación de propuestas y sugerencias, a través de los trámites de consulta previa a la redacción del texto de la iniciativa a través del portal web de la Administración correspondiente, de audiencia e información pública (art. 133 LPACAP) ${ }^{14}$.

Es cierto que el art. 133.4 LPACAP prevé que podrán prescindirse de los referidos trámites cuando se den determinados supuestos, pero ninguno de ellos se presenta cuando se está tramitando una Carta de Servicios. Está claro que no es una norma presupuestaria. Tampoco se trata de una norma organizativa de la Administración, puesto que, aunque es cierto que regula internamente cómo la Administración ha de prestar un servicio, tiene claros efectos jurídicos ad extra, frente a terceros, los usuarios de esos servicios, que se ven directamente afectados por los requisitos de acceso que en la Carta se fijen así como por los estándares de calidad que se adopten. Y por último, es difícil imaginar que en un supuesto de elaboración de una Carta de Servicios concurran graves razones de interés público.

Para dar cumplimiento al derecho de disfrutar de unos servicios públicos dotados de «unas condiciones mínimas y razonables de calidad», es imprescindible conocer cuáles son las necesidades y expectativas de los ciudadanos y, en especial, de los usuarios de aquéllos. Hay que darles voz en el procedimiento de elaboración de la Carta y, asimismo, cuando el servicio esté prestándose, valorar las sugerencias que formulen como camino para avanzar en la mejora continua de la calidad del servicio.

Es precisamente el efecto ad extra que despliega el contenido de una Carta de Servicios, lo que la distingue de los reglamentos internos, de tipo organizativo, y de instrumentos como pueden ser las Relaciones de Puestos de Trabajo (RPT), de los que se valen las Administraciones para la organización de sus efectivos públicos, con una naturaleza jurídica controvertida y con un procedimiento de elaboración flexible, aunque con una serie de trámites obligatorios ${ }^{15}$.

A diferencia del art. 59 LTAIPBGC, que no establece ningún trámite obligatorio durante el procedimiento de elaboración y tramitación normativa de la Carta de Servicios, el art. 42.4 de la Ley gallega 1/2015, establece como requisito necesario y previo a la aprobación de la Carta por Orden del titular de la Consejería de la que dependa el órgano, servicio o unidad responsable de la prestación del servicio público, que conste un «informe favorable» de la Consejería competente en materia de gestión y evaluación de la calidad de los servicios públicos. La Ley gallega, en el art. 42.5, remite el desarrollo de la metodología de elaboración, gestión y actualización de las Cartas de Servicios a un futuro Decreto de la Junta de Galicia.

Es por ello que, tras seguir los trámites fundamentales que establece la Ley 39/2015 con relación a la tramitación de normas reglamentarias, la Carta de Servicios será aprobada por el órgano competente y adoptará la forma de Decreto, Orden u Ordenanza municipal ${ }^{16}$, siendo publicada en los Boletines Oficiales correspondientes y páginas webs institucionales.

En este sentido, el art. 59 LTAIPBGC dispone que, al tener las Cartas de Servicios naturaleza reglamentaria, deben ser aprobadas por Decreto u Orden, en el caso de la Generalidad de Cataluña o, en el caso

14 En el estudio del profesor José Luis MARTÍNEZ LÓPEZ-MUÑIZ sobre las novedades legislativas en materia de elaboración de reglamentos, advierte sobre la inexistencia de controles de legalidad disponibles frente al incumplimiento por una Administración o su Gobierno de las normas que la Ley 39/2015 contempla sobre la iniciativa legislativa. Vid. "La elaboración de los reglamentos", en Innovaciones en el Procedimiento Administrativo Común y el Régimen Jurídico del Sector Público, ob. cit., págs. 313-314.

${ }_{15}$ Respecto a la naturaleza jurídica de las RPT, Francisco Jesús FERREIRO SEOANE expone que ha oscilado entre quienes las consideraban normas jurídicas y los que entendían que eran actos administrativos con destinatario general. Mas, desde la STS de 5 de febrero de 2014, se mantiene que su naturaleza es de acto-condición administrativo, ordenado y no ordenador de los efectivos públicos. En cuanto al procedimiento de elaboración de una RPT señala que, aún siendo flexible, hay una serie de trámites obligatorios. Así, en la elaboración de una RPT de una Administración local destacan como obligatorios los de la fase de negociación, aprobación provisional por el Pleno, trámite de información pública, aprobación definitiva, publicación íntegra en el Boletín Oficial de la Provincia, junto con el resumen de los presupuestos y remisión de una copia de la misma a la Administración General del Estado y a la CA respectiva en el plazo de 30 días. Una vez aprobada y publicada la RPT, es de obligado cumplimiento en todas sus partes y vincula a la Administración. Vid. "La RPT como un instrumento de organización de las administraciones locales", REALA, núm. 5 (enero-junio 2016). https://doi. org/10.24965/reala.v0i5.10349.

${ }_{16}$ El procedimiento de «elaboración» de normas reglamentarias establecido en la Ley 39/2915, aplicable a las ordenanzas y reglamentos municipales, no afecta al procedimiento de «aprobación» de éstos regulado en el art. 49 de la Ley de Bases de Régimen Local. Sobre la implementación de las nuevas previsiones de la LPACAP al procedimiento de elaboración y aprobación de los reglamentos locales vid. Alejandro Ramón ANTELO MARTÍNEZ, "Elaboración de disposiciones de carácter general en la Administración Local, tras la entrada en vigor de la Ley 39/2015", REALA, núm. 6 (2016), págs. 105-121. https://doi.org/10.24965/reala.v0i5.10391. 
de las entidades locales, por el instrumento que establezca la normativa local, siendo las mismas objeto de publicación en los Diarios Oficiales correspondientes.

Por su parte, el art. 9.1.j) LTAIPBGC contempla el deber de la Administración de hacer pública la información relativa a «El catálogo de los servicios prestados, las cartas de servicios existentes y la información sobre los resultados de las evaluaciones de calidad y de la incidencia social de las políticas públicas».

Por último, el art. 10.1.c) de la Ley 29/2010, de 3 de agosto, del Uso de los Medios Electrónicos en el Sector Público de Cataluña contempla la obligación de las entidades que conforman su sector público de difundir por medios electrónicos e informar a los ciudadanos de los servicios que prestan, y uno de los medios que explicita son las Cartas de Servicios.

\subsection{Efectos vinculantes}

Consecuencia de la naturaleza reglamentaria que el art. 59.2 LTAIPBGC atribuye a las Cartas de Servicias es su efecto vinculante para la Administración prestadora, pudiendo los usuarios del servicio invocar el contenido de aquéllas vía reclamación, con el doble propósito de, por un lado, penalizar el incumplimiento de los compromisos de calidad acordados y, por otro, incentivar el cumplimiento de los mismos en el futuro y la mejora continua de la prestación del servicio.

Por su parte, en el caso de que el funcionamiento del servicio haya causado un daño al usuario, el análisis del cumplimiento de los estándares de calidad aprobados en la Carta de Servicios tendrá una enorme relevancia a la hora de determinar la existencia de la responsabilidad patrimonial de la Administración, tal y como analizaremos en el último apartado.

\subsection{Evaluación y actualización}

El nuevo apartado $4 .^{\circ}$ del art. 23 LRJPAPC establece el deber de evaluar las Cartas de Servicios cada dos años, así como el deber de actualización, como mínimo, cada cinco años.

La evaluación de las Cartas puede hacerse por órganos internos de la propia Administración u órganos externos, siendo conveniente que aumente el número de Cartas que tras ser evaluadas cuenten con un reconocimiento y acreditación del grado de calidad de su contenido y sus compromisos, por ejemplo, según las normas ISO ${ }^{17}$.

El papel de la ciudadanía es fundamental en el proceso de evaluación de la calidad de los servicios públicos, y ello se refleja en el derecho que el art. 60 LTAIPBGC reconoce a los usuarios del servicio a ser consultados, generalmente a través de encuestas, respecto a su grado de satisfacción en cuanto a los servicios públicos y las actividades gestionadas por la Administración Pública, cuyos resultados deberán publicarse en el Portal de la Transparencia. Asimismo, el art. 61 de esta Ley también reconoce el derecho de los ciudadanos a realizar a través del Portal de la Transparencia, o por cualquier otro medio que escojan, propuestas de actuación o mejora y sugerencias con relación al funcionamiento de los servicios públicos.

Estas propuestas, sugerencias e información que la Administración recaba de los usuarios deberán ser tenidas en cuenta a la hora de actualizar el contenido de las Cartas de Servicios.

\section{SITUACIÓN DE LAS CARTAS DE SERVICIOS TRAS LA LEY 19/2014}

En este apartado vamos a comentar cuál ha sido el proceso de implantación del nuevo modelo de las Cartas de Servicios y el de adaptación de las ya existentes desde que entrara en vigor la Ley 19/2014.

\section{Informes del Sindic de Greuges}

En el Informe sobre transparencia, acceso a la información pública y buen gobierno, publicado en julio de 2016, el Síndic de Greuges de Cataluña subraya la naturaleza reglamentaria de las Cartas de Servicios y la gran novedad que supone este carácter obligatorio con respecto a la situación precedente a la Ley

17 Este sería el caso de la Carta de Servicios de la Oficina de Atención Ciudadana de Gerona, cuyos compromisos de calidad tienen reconocido desde el 8 de junio de 2015 un certificado de calidad según la norma ISO 9001:2008 (núm. de certificado ES064925-1). 
19/2014. Mas, del análisis realizado, concluye que el número de Cartas de Servicios que han sido aprobadas tras la citada Ley con contenido jurídicamente vinculante es muy limitado. Asimismo, respecto a la revisión profunda que precisan las Cartas de Servicios aprobadas con anterioridad a la LTAIPBGC, el Síndic de Greuges reconoce que, en términos generales, en el momento en el que se solicitó información a la Administración de la Generalidad y algunos de los municipios de mayor dimensión, no se había realizado.

Ante esta situación, el Síndic de Greuges propone que se elaboren «modelos tipo» de Cartas de Servicios, que sirvan de guía por lo que respecta al procedimiento de elaboración a seguir y en cuanto al contenido mínimo obligatorio. De esta manera se facilitaría, sobre todo a un gran número de entidades obligadas a su aprobación y que no cuentan con experiencia previa en esta materia, el cumplimiento de la obligación legal que impone el art. 59 LTAIPBGC ${ }^{18}$.

Meses más tarde, en el Informe al Parlamento 2016, publicado en febrero de $2017^{19}$, el Sindic de Greuges concluye que los cambios y transformaciones que propugna la Ley de Transparencia no pueden vincularse tan sólo a la entrada en vigor formal de ésta o al cumplimiento de las obligaciones legales, y constata que «en las obligaciones que requieren la elaboración de nuevos instrumentos (códigos éticos, procesos participativos, por poner dos ejemplos) o reelaborar los ya existentes (cartas de servicios con contenido exigible, entre otros), (...) el cumplimiento se ha retrasado más allá de la entrada en vigor de la Ley y del momento en el que se analizaron los datos».

En la misma línea se expresa el Síndic en el Informe sobre transparencia, acceso a la información pública y buen gobierno, de julio de $2017^{20}$, y en el Informe al Parlamento 2017, de febrero de $2018^{21}$. En ellos pone de manifiesto que, pasados ya dos años desde la entrada en vigor de la LTAIPBGC, es difícilmente justificable la situación de incumplimiento de la Ley en esta materia. Tras enviar un cuestionario a las entidades obligadas por la Ley 19/2014 a aprobar Cartas de Servicios y requerirles copia de las mismas para su análisis, solo se recepcionaron 23 Cartas, y de ellas, solo 4 cumplían con los dos requisitos exigidos por el art. 59, adaptándose al contenido mínimo obligatorio y reconociendo su naturaleza normativa. Por consiguiente, un año más tarde, el Síndic reitera la recomendación que ya hiciera en su informe de 2016, sobre la conveniencia de elaborar un «modelo tipo» de Carta de Servicios por parte de la Generalidad que impulse la elaboración y/o adaptación de las mismas por los sujetos obligados y revierta la situación actual ${ }^{22}$.

\section{Procedimiento para la elaboración de las Cartas}

El art. 59.3 LTAIPBGC contempla la obligación de que las Cartas de Servicios en el ámbito de la Administración de la Generalidad de Cataluña sean aprobadas por Decreto del Gobierno o por Orden de la persona titular de la Consejería competente. En el caso de los consejos comarcales, los municipios de gran población y los consejos de veguería, la Ley hace una remisión a lo que se determine en la legislación de régimen local, por lo tanto, habrán de ser aprobadas por el Pleno del Ayuntamiento.

En este contexto, hay que decir que la Generalidad de Cataluña cuenta ya con un documento que puede servirnos de base para dicho propósito. En enero de 2008, la Generalidad publicó una Guía para la Elaboración de Cartas de Servicios en Cataluña, elaborada por la Dirección General de Modernización de la Administración del Departamento de Gobernación y Administraciones Públicas. Dicho documento sólo necesitaría una revisión parcial, adaptándolo a la nueva naturaleza reglamentaria y a las novedades respecto al contenido y efectos vinculantes que exige la LTAIPBGC.

18 Puede consultarse el citado informe en $h$ ttp://www.sindic.cat/site/unitFiles/4163/Informe\%20llei\%20transparencia\%20a\%20Catalunya_cast_def.pdf. Vid. en especial, págs. 29-30 y 42.

${ }_{19}$ Puede consultarse en http://www.sindic.cat/site/unitFiles/4301/Informe\%20al\%20Parlamento\%202016_ok.pdf. Vid. págs. 127-128.

20 Vid. en http://www.sindic.cat/site/unitFiles/4584/Informe\%20transparencia2017_cast_ok.pdf, págs. 29-30 y 43.

${ }^{21}$ Vid. pág. 131 del Informe al Parlamento, accesible en $h t t p: / / w w w . s i n d i c . c a t / s i t e /$ unitFiles/5012/Informe\%20al\%20Parlament\%20 2017\%20cat.pdf.

${ }_{22}$ Según se indica en las págs. 7 y 72 del documento "Grupos de interés, buen gobierno, buena administración, calidad normativa y sistema de garantías" que forma parte del II Informe de evaluación ex post de la Ley 19/2014, de abril de 2017, el Comité Interdepartamental de Transparencia y Gobierno Abierto (CITGO) tiene actualmente elaboradas unas instrucciones sobre la aprobación y la publicación de las Cartas de Servicios de la Administración de la Generalidad de Cataluña y sus entes del sector público; asimismo, están puestos en marcha siete proyectos piloto de elaboración de Cartas de Servicios según la normativa vigente («Serveis de Gestió Empresarial - OGE - FUE. Serveis d'Atenció Ciutadana - OCAC Girona. Serveis d'Atenció Ciutadana - OAC TES. Serveis de mesures penals alternatives DGEPC. Serveis d'atenció primària de salut - SCS Autònom. Serveis estadístics - IDESCAT. Serveis audiovisuals CCMA». Vid. http://www.sindic.cat/site/unitFiles/4586/II\%20Informe\%20avaluació\%20Llei\%2019_2014_resta\%20obligacions.pdf. 
Para abordar esta tarea, resulta útil hacer un análisis comparado de documentos aprobados en esta materia por otras Administraciones, como pueden ser: el Marco Común sobre las Cartas de Servicios en las Administraciones Públicas Españolas, de la AEVAL (2015); el Manual para la Elaboración de una Carta de Servicios ${ }^{23}$, de la Consejería de Presidencia y Administraciones Públicas de Castilla-La Mancha (2013); o la Guía Elaboración y Gestión de una Carta de Servicios en la Administración Local ${ }^{24}$, de la Federación Española de Municipios y Provincias (2011).

En definitiva, ya opte la Generalidad por redactar un nuevo documento o por revisar la Guía de 2008, lo cierto es que para implementar efectivamente las nuevas Cartas de Servicios es más que conveniente que se cuente con un Manual o Guía de elaboración y un modelo tipo de Carta de Servicios a seguir ${ }^{25}$.

En este contexto, consideramos que pueden jugar un importante papel las Diputaciones, impulsando, apoyando y ayudando a los Ayuntamientos con las tareas de elaboración de las Cartas de Servicios.

\section{Análisis de las Cartas de Servicios aprobadas o revisadas}

Tomando como referencia el Informe de evaluación ex post de la aplicación de la Ley 19/2014 de Transparencia, Acceso a la Información Pública y Buen Gobierno de Cataluña, elaborado por los profesores Manuel Villoria, Agustí Cerrillo y Juli Ponce y el investigador Albert Urrutia ${ }^{26}$, que sirve de base al informe sobre transparencia del Sindic de Greuges de julio de 2016, se extraen los siguientes datos:

En primer lugar, de los municipios de más de 50.000 habitantes, hay 4 Ayuntamientos que tienen Cartas de Servicios bien estructuradas. Más de la mitad de los municipios no disponen de Cartas. Un Ayuntamiento tiene 30 Cartas, otro 19, otro 15 y otro 26. Las Cartas aprobadas se refieren principalmente a servicios de seguridad, hacienda, consumo, comercio, salud y servicios sociales. De las 76 Cartas que contienen indicadores para su evaluación, sólo en dos casos han realizado dicho tarea de evaluación.

En segundo lugar, de los municipios de entre 20.000 y 50.000 habitantes, hay 5 municipios que en total tienen 191 Cartas de Servicios, aunque 171 Cartas corresponden a uno de ellos. Un $80 \%$ de los municipios de esta tipología no tienen Cartas de Servicios. Los servicios en los que se centran son sobre todo los de: urbanismo y territorio, medio ambiente, educación, salud y servicios sociales. En 6 Cartas se contienen indicadores para evaluar la aplicación de la Carta, pero ninguno lo hace.

En tercer lugar, de los municipios de entre 5.000 y 20.000 habitantes, 6 sí tienen Cartas (61 del total de 70 son de un mismo municipio). Los servicios concretos que se regulan son los de consumo/comercio, medio ambiente, salud y servicios sociales. En 48 Cartas hay indicadores para evaluar su aplicación, y solo hay tres que lo hacen.

En cuarto lugar, de los municipios entre 500 y 5.000 habitantes, hay 8 que afirman que tienen Cartas de Servicios en multitud de áreas. Del total de 178 Cartas, 60 son de un solo municipio. Los servicios que regulan son los de urbanismo, medio ambiente, salud, servicios sociales, educación y hacienda. En este caso no hay información sobre cuántas de estas Cartas contienen indicadores de evaluación, no obstante, 4 municipios proceden a la evaluación de sus Cartas.

En quinto lugar, con relación a las Diputaciones, hay una Diputación que tiene 10 Cartas de Servicios que regulan todas las competencias de la Diputación por áreas. En las 10 Cartas se contienen indicadores para evaluar su aplicación, habiéndose evaluado en una ocasión.

En sexto lugar, los consejos comarcales cuentan con 107 Cartas en áreas de sus competencias, como salud y servicios sociales, educación, cultura, empleo y medio ambiente, no habiéndose evaluado la aplicación de las mismas.

23 Puede consultarse este Manual en $h t t p: / / w w w . c a s t i l l a l a m a n c h a . e s / s i t e s / d e f a u l t / f i l e s / d o c u m e n t o s / p d f / 20130926 /$ manual_para_ la_elaboracion_de_una_carta_de_servicios_sept_2013.pdf.

${ }_{24}$ Puede consultarse esta Guia en http://www.aeval.es/export/sites/aeval/comun/pdf/calidad/guias/Guia carta_servicios_Administracion_Local.pdf.

${ }_{25}$ En la dirección http://governacio.gencat.cat/web/.content/modernitzacio de I administracio/modernitzacio de I administracio/documents/arxius/guia_cartes_de_serveis.pdf, junto a la citada Guía de 2008, aparece un icono con el título Manual de estilo aplicable para la elaboración de las Cartas de Servicios, no obstante, a fecha de 3 de julio de 2017, sin contenido, con el mensaje «este apartado está en actualización».

26 Vid. en especial las págs. 51-56 del informe de 2016, que puede consultarse, junto con los documentos del equipo, en $h t t p: / /$ www2. sindic. cat/ca/page. $a s p ? i d=356$. 
En séptimo lugar, con relación a las 6 Universidades que contestaron el cuestionario remitido, se cuenta con un total de 61 Cartas de Servicios aprobadas, siendo 50 de una sola de ellas. En estas Cartas se contienen indicadores para evaluar su aplicación, pero ninguna Universidad lo ha realizado.

Y en octavo lugar, por parte de la Generalidad de Cataluña y sus entidades sólo se facilitaron datos sobre 5 Cartas de Servicios del Departamento de Territorio y Sostenibilidad aprobadas tras la Ley 19/2014, no comunicándose datos sobre las aprobadas con anterioridad, pues entendía la Administración que no daban respuesta a las cuestiones que se formulaban en el cuestionario que se les facilitaba. De acuerdo con este informe, las 5 Cartas cumplen con todas las condiciones de la Ley 19/2014. Las 5 Cartas tienen indicadores de evaluación, habiéndose evaluado 4 de ellas.

En todas las Cartas de Servicios sometidas al cuestionario, ninguna ha tenido reclamaciones ni acciones judiciales.

A la vista de las cifras y datos mostrados, en el comentado informe de 2016 se concluye que los principios de buena administración no se han trasladado a las Administraciones Públicas catalanas, las cuales no reconocen el carácter normativo que sus Cartas de Servicios tienen de acuerdo con el art. 59.2 LTAIPBGC, quedando bastante trabajo por hacer, sobre todo, en los municipios más pequeños que, con alguna excepción, no han abordado este tema.

Con posterioridad a la elaboración del referido informe, han sido aprobadas por la Comisión de Gobierno del Ayuntamiento de Barcelona, en su sesión de 15 de diciembre de 2016, de conformidad con lo prescrito en los arts. 9.1.j) y 59 LTAIPBGC, las siguientes doce Cartas de Servicios: de Presidencia y Economía; del Archivo Municipal; del Servicio de Documentación y Acceso al Conocimiento; de Comercio; de Derechos de la Ciudadanía y Participación; de Atención Ciudadana; de Derechos Sociales; de Urbanismo; de Medio Ambiente y Servicios Urbanos; de Movilidad e Infraestructuras; de Población; y de Vivienda ${ }^{27}$.

Y entre las Cartas de Servicios que se han aprobado por la Generalidad de Cataluña tras la entrada en vigor de la LTAIPBGC se encuentran las de ${ }^{28}$ : Atención Ciudadana, del Departamento de la Presidencia (de mayo de 2015); la Oficina de Atención Ciudadana en Gerona (actualizada a 8 de julio de 2016); Atención Ciudadana de la Secretaría de Universidades e Investigación (de 25 mayo de 2015); Gestión de Centros Logísticos de Cataluña de CIMALSA (revisada en marzo de 2015); y la Agencia Tributaria de Cataluña (actualizada a 14 de julio de 2016).

Tras el análisis de estas nuevas Cartas, pueden seguir manteniéndose las conclusiones del informe comentado anteriormente. En estas Cartas no se plasma, o al menos no se manifiesta expresamente, el cambio de naturaleza y de efectos jurídicos.

Asimismo, debiera revisarse el contenido de los compromisos de calidad recogidos en algunas de las Cartas de Servicios actualmente vigentes, en el sentido de que éstos realmente proporcionen un plus de calidad y no sean mera reproducción de obligaciones impuestas legalmente. Un compromiso de calidad no es cumplir con los plazos máximos legalmente establecidos para resolver determinados procedimientos, lo sería comprometerse a resolver esos procedimientos en un tiempo menor que el fijado por la norma como máximo.

Una muestra: el caso de la Carta de Servicios del Institut Municipal D'Hisenda, revisada en enero de 2016. Entre los compromisos relativos a la tramitación de documentos prevé con relación a las alteraciones catastrales que se tramitarán en un plazo inferior a seis meses. De acuerdo con el Texto Refundido de la Ley del Catastro Inmobiliario aprobado por el Real Decreto Legislativo 1/2004, de 5 de marzo, desarrollado por el Real Decreto 417/2006, el plazo máximo de resolución es de seis meses. Igualmente, con respecto a los compromisos relativos a la resolución de incidencias por devolución de ingresos se establece que en el $90 \%$ de los casos las devoluciones se efectuarán en un plazo inferior a seis meses desde que quede reconocido el derecho a la devolución. Pues bien, de acuerdo con la Ley General Tributaria y el Real Decreto 520/2005, de 13 de mayo, que aprueba el Reglamento general de desarrollo de la citada Ley, se establece como plazo máximo de resolución 6 meses. En consecuencia, nos falta fijar un plus de calidad, de compromiso, que fijara por ejemplo, que los citados procedimientos se resolverán en el plazo máximo de cinco meses. Además, en el caso de las devoluciones, el Institut se compromete a cumplir el plazo máximo que fija la Ley en un $90 \%$ de los casos, ¿qué pasa con el $10 \%$ restante?

27 Puede consultarse el texto de las mismas en la Gaceta Municipal de Barcelona número 2, de 20 de enero de 2017 , en el Boletín de la Provincia de Barcelona de 31 de enero de 2017 y en el Portal de la Transparencia de la página web del Ayuntamiento de Barcelona (http://ajuntament.barcelona.cat/transparencia/sites/default/files/acord_aprovacio_bop_0.pdf).

28 Pueden consultarse en http://governacio.gencat.cat/ca/pgov_ambits_d_actuacio/pgov_funcio_publica/pgov_processos-administracio-electronica/pgov_millora_simplificacio_processos/cartes-de-serveis/. 
Otro supuesto: el de la Carta de Servicios de la Agencia Tributaria de Cataluña (actualizada a 14 de julio de 2016). En ella se contempla la interposición de quejas ante la Oficina del Contribuyente y se expone el régimen de interposición del recurso de reposición y las reclamaciones económico-administrativas, lo cual no es más que reproducción del régimen de recursos aplicable contra los actos administrativos en materia tributaria, pero no un reconocimiento de exigibilidad de otro tipo de contenido obligatorio con relación al cumplimiento de los estándares de calidad que con respecto a la prestación de los servicios que gestiona la Agencia se establezcan en la Carta como compromisos de calidad.

Hay también alguna Carta, como la de la Agencia del Agua (de diciembre de 2015) que, pese a no citar a la LTAIPBGC, contempla no sólo el derecho de los ciudadanos a presentar quejas y sugerencias, sino a interponer un recurso ante la Agencia en caso de disconformidad con su actuación.

Un caso particular, en el que se mezclan los conceptos de Catálogo y Carta de Servicios, es el Catálogo de Servicios 2017 de la Diputación Provincial de Barcelona, certificado por AENOR conforme a la norma UNE 93200:2008. Nos encontramos ante un documento extenso, resultado de la suma de múltiples Cartas de Servicios. Para el 2017 se asumen cuatro compromisos de calidad general para todo el Catálogo y 316 para el total de los recursos ofertados. Su estructura y extensión puede resultar perfectamente válida y acertada desde el punto de vista de la organización administrativa interna, pero no parece que se trate de un documento fácil de manejar para la mayoría de la ciudadanía, con el que de forma rápida y sencilla quede informada de los derechos que le asisten y los compromisos de calidad que cada órgano asume respecto de un servicio. Por otra parte, es llamativo que, pese a su reciente aprobación y citar las Leyes autonómicas de Transparencia y de Procedimiento Administrativo, no alude a la naturaleza jurídica ni a los efectos efectos jurídicos que tienen estos instrumentos conforme a la nueva regulación ${ }^{29}$.

Por su parte, el II Informe de evaluación ex post de la aplicación de la Ley 19/2014 de Transparencia, Acceso a la Información Pública y Buen Gobierno de Cataluña. Grupos de interés, buen gobierno, buena administración, calidad normativa y sistema de garantías, de abril de 2017, elaborado por los profesores Juli Ponce y Manuel Villoria ${ }^{30}$, y que sirve de base al informe sobre transparencia del Sindic de julio de 2017, pone de manifiesto lo lejos que en este tema se está de una situación ideal, dado el bajísimo cumplimiento de la LTAIPBGC por parte de las Administraciones catalanas. De las 32 respuestas que pudieron ser analizadas ( 3 de la Generalidad, 2 de Universidades y 27 de entes locales), 2 no se ajustaban a la ley, 4 no eran realmente Cartas de Servicios sino meros catálogos o listas de trámites y otras 3 no eran nada en realidad. De esas 23 muestras restantes, sólo en 4 casos se cumplía con el contenido mínimo legal obligatorio y con el reconocimiento de la Carta de Servicios como norma (se trata de las Cartas de Servicios de los Ayuntamientos de Reus y de Santa Coloma de Gramanet, aprobadas por sus respectivos Plenos; las del Ayuntamiento de Barcelona, por la Comisión de Gobierno; y la del Ayuntamiento de Molins, por Decreto de Alcaldía).

En suma, en la actualidad, el grupo más numeroso de Cartas de Servicios aprobadas en Cataluña es el de las que aún no han adaptado su contenido a la LTAIPBGC, estando pendiente su revisión y actualización ${ }^{31}$.

\section{Plazo para la aprobación de las nuevas Cartas}

De conformidad con la Disposición Final $4 .^{a}$ LTAIPBGC, el contenido de la Ley, salvo el del título II y el referido a la Comisión de Garantías del Derecho de Acceso a la Información Pública, entró en vigor a los seis meses de su publicación en el Diario Oficial de la Generalidad de Cataluña, esto es, el 1 de julio de 2015.

La Disposición Final 3. ${ }^{a}$ LTAIPBGC habilita al Gobierno de la Generalidad de Cataluña para dictar las disposiciones necesarias para el correcto desarrollo y aplicación de la Ley, sin perjuicio del deber de los entes locales «de adoptar las medidas normativas y ejecutivas que sean necesarias» para aplicarla, de acuerdo con el principio de autonomía organizativa.

Según el tenor de estas disposiciones, pueden sostenerse dos interpretaciones: la primera, que todas las Cartas de Servicios, tanto de la Administración autonómica como local de Cataluña, debían estar apro-

${ }^{29} \mathrm{Vid}$. https://seuelectronica.diba.cat/tramits-ens/concertacio/cataleg2017/compromisos_qualitat.asp.

30 Vid. págs. 64-87 del referido documento, http://www.sindic.cat/site/unitFiles/4586/II\%20Informe\%20avaluació\%20L/ei\%20 19_2014_resta\%20obligacions.pdf.

31 Como son los casos de las Cartas de Servicios de: la Dirección General de Prevención, Extinción de Incendios y Salvamentos, aprobada el 21 de enero de 2010, aunque la edición impresa de la Carta del Servicio de Bomberos de la Generalidad de Cataluña es de diciembre de 2009; del Palau Robert (julio de 2014); de la Biblioteca de la Generalitad de Cataluña (actualizada a 2014); y de Centros de Iniciativa para la Reinserción (marzo 2014). 
badas a la entrada en vigor de la LTAIPBGC; y la segunda, que el impulso y aprobación de estas Cartas quedaba en manos de los responsables de cada servicio ${ }^{32}$.

Con base en la Disposición Final 4. ${ }^{\text {a }}$.1, cobra más peso la primera interpretación, por lo que a fecha de 1 de julio de 2015 deberían haber estado, si no todas las Cartas de Servicios aprobadas, sí al menos iniciadas las tareas de revisión de las Cartas aprobadas con anterioridad para proceder a su adaptación a los nuevos contenidos de la LTAIPBGC, así como iniciados los procedimientos de tramitación normativa de las nuevas Cartas.

Existe una reiterada jurisprudencia del TS $^{33}$ que establece que se puede recurrir y condenar a la Administración por la falta de elaboración de un reglamento cuando existe una obligación legal de dictarlo, como sucede con las Cartas de Servicios en Cataluña tras la LTAIPBGC. Tal y como comenta el profesor Ponce Solé, estamos ante una obligación legal que «si se incumple fuera del tiempo razonable que imponen las obligaciones de buena administración supondría una vulneración del derecho previsto en el art. $30 \mathrm{EAC})^{34}$.

En efecto, esta situación exige de un «buen gobierno», de políticos responsables y conscientes de su obligación de impulsar la elaboración de Cartas de Servicios, que contemplen estándares realistas, alcanzables y de calidad, manifestación ésta del derecho de los ciudadanos a una «buena administración» y que, en Cataluña, son de cumplimiento obligatorio ${ }^{35}$.

Recordemos que entre los principios que fundamentan el gobierno abierto, el art. 65.1 LTAIPBGC cita los de «la mejora continua de la calidad de los servicios» (letra e) y «la rendición de cuentas y la asunción de responsabilidad ante los ciudadanos derivada de las decisiones adoptadas» (letra g). Y en este contexto, la Ley 19/2014 regula los Códigos de Conducta como instrumentos de «buen gobierno» con relación a los altos cargos de la Administración, tanto autonómica ${ }^{36}$ como local, aunque en este último caso su aprobación no es obligatoria ${ }^{37}$.

Lo cierto es que pasado el ecuador de 2017, el número de Cartas aprobadas sigue siendo muy reducido. ¿Qué puede hacerse ante la inactividad de la Administración? Pues, tal y como opina el profesor Ponce Solé ${ }^{38}$, puede acudirse al orden jurisdiccional contencioso-administrativo por inactividad, previo requerimiento ante la Administración que esté obligada a aprobar la Carta de Servicios, con base en el incumplimiento de las obligaciones de buena administración, de acuerdo con lo dispuesto en el art. 25 y 29 de la Ley 29/1998, de 13 de julio, de la Jurisdicción Contencioso-administrativa. Asimismo, también sería dicha vía de reclamación la que procedería seguir en el supuesto de que la Carta sí esté aprobada pero el servicio no sea prestado por la Administración ${ }^{39}$.

32 Vid. Juli PONCE SOLÉ, "Bon govern, dret a una bona administració i prevenció de la corrupció", en Transparència, accés a la informació pública i bon govern a Catalunya: Comentaris sobre la Llei 19/2014, de 9 de desembre, ob. coord. por Agustí CERRILLO I MARTÍNEZ y Juli PONCE I SOLÉ, editorial UOC, Barcelona, 2015, págs. 177-218, en especial, sobre las Cartas de Servicios, págs. 199-204.

${ }^{33}$ La Sala de lo Contencioso-administrativo del TS tiene sentado que: «únicamente cabe apreciar una ilegalidad omisiva controlable jurisdiccionalmente, cuando, siendo competente el órgano titular de la potestad reglamentaria para regular la materia de que se trata, la ausencia de previsión reglamentaria supone el incumplimiento de una obligación expresamente establecida por la Ley que se trata de desarrollar o ejecutar, o cuando el silencio del Reglamento determine la creación implícita de una situación jurídica contraria a la Constitución o al ordenamiento jurídico». Vid. al respecto SSTS: de 28 junio 2004 (RJ 2004l4989), FJ 2. ${ }^{\circ}$; de 11 de noviembre de 2008 (RJ 200816668), FJ 2. ${ }^{\circ}$; de 5 de julio de 2011 (RJ 2011/6191), FJ 5..$^{\circ}$ de 13 de octubre de 2011 (RJ 2011/7254), FJ 4. . ; de 27 de noviembre de 2012 (RJ 2013।434), FJ 2..$^{\circ}$ de 14 de mayo de 2013 (RJ 2013\4233), FJ 6. ; de 28 de noviembre de 2014 (RJ 2014l6229), FJ 7.' ; y de 19 de enero de 2015 (RJ 2015 283), FJ 3.'.

${ }_{34}$ Vid. Juli PONCE SOLÉ, "Bon govern, dret a una bona administració i prevenció de la corrupció", ob. cit., pág. 200.

35 Sobre las diferencias existentes entre las nociones de buen gobierno, buena administración y buena gobernanza, vid. Juli PONCE SOLÉ, "La discrecionalidad no puede ser arbitrariedad y debe ser buena administración", REDA, núm. 175 (enero-marzo 2016), págs. 65-66 y su introducción a la obra colectiva por él dirigida junto a Agustí CERRILLO I MARTÍNEZ, Innovación en el ámbito del buen gobierno regulatorio: ciencias del comportamiento, transparencia y prevención de la corrupción, INAP, Madrid, 2017.

${ }^{36}$ Vid. el Acuerdo GOV/82/2016, de 21 de junio, por el que se aprueba el Código de conducta de los altos cargos y personal directivo de la Administración de la Generalidad y de las entidades de su sector público, y otras medidas en materia de transparencia, grupos de interés y ética pública (publicado en el Diario Oficial de la Generalidad de Cataluña núm. 7.148, de 23 de junio de 2016). Otro ejemplo es el Código de conducta de los miembros del Parlamento de Cataluña (publicado en el BOE, núm. 249, de 14 de octubre de 2016).

37 El contenido mínimo de estos se regula en el art. 51 LTAIPBGC, que serán objeto de desarrollo vía reglamento, según prescribe el art. 53 de esta Ley. El incumplimiento de su contenido tiene claros efectos sancionadores.

${ }^{38}$ Vid. Juli PONCE SOLÉ, "Bon govern, dret a una bona administració i prevenció de la corrupció", ob. cit., pág. 201 y en el ya citado II Informe de evaluación ex post de la aplicación de la Ley 19/2014, de abril de 2017, pág. 69.

${ }_{39}$ Un concepto que emplea Ricardo DE VICENTE DOMINGO y que resulta muy útil a la hora de determinar cuándo la Administración cumple con el nivel mínimo que deben tener sus actuaciones es el de «suficiencia de la actividad», vid. "Discrecionalidad e inactividad. El principio de actuación suficiente", REDA, núm. 165 (2014), págs. 71-102. 
Ante la falta de iniciativa normativa por parte de la Administración Pública correspondiente a la hora de elaborar y presentar un proyecto normativo, como el de una Carta de Servicios, recordemos que el art. 70 LTAIPBGC ${ }^{40}$ establece que las personas legitimadas para promover la iniciativa legislativa popular ${ }^{41}$ «tienen el derecho a presentar a la Administración pública propuestas de iniciativa normativa de carácter reglamentario», que deberá estar avalada por más de 15.000 firmas si la propuesta se presenta ante la Generalidad. El órgano competente para iniciar el procedimiento de tramitación normativa habrá de valorar la propuesta, adoptar y notificar su decisión al respecto en el plazo máximo de tres meses y deberá exponer las razones por las que es aceptada o rechazada. La falta de resolución en plazo se concibe por la Ley como un supuesto de desestimación por silencio administrativo.

En este contexto, estoy convencida de que las Oficinas por la Transparencia y las Buenas Prácticas, como la creada por el Ayuntamiento de Barcelona el 26 de noviembre de 2016, están llamadas a jugar un papel fundamental, ya que son una canal creado por el Ayuntamiento para que la ciudadanía ponga de manifiesto todas aquellas conductas y prácticas contrarias a los principios de transparencia y de buen gobierno y que supongan un incumplimiento de la legalidad, como puede ser la falta de aprobación de Cartas de Servicios conforme al contenido de la LTAIPBGC.

\section{CONSECUENCIAS DEL INCUMPLIMIENTO DE LOS ESTÁNDARES DE CALIDAD EN EL PLANO DE LA RESPONSABILIDAD PATRIMONIAL DE LA ADMINISTRACIÓN}

\section{Referencia a la nueva regulación de la responsabilidad patrimonial}

Como ponen de relieve destacados administrativistas, vivimos un momento de reinterpretación del papel que corresponde al Estado -como «garante»- y a la Administración del siglo XXI y de la Era de la Información. Consecuencia de esa transformación del Estado y su relación con la sociedad surge la necesidad de revisar muchas técnicas e instituciones tradicionales del Derecho Administrativo ${ }^{42}$.

Desde hace un par de décadas, una parte destacada de la doctrina viene reclamando un nuevo planteamiento del alcance del sistema de responsabilidad patrimonial de las Administraciones Públicas españolas ${ }^{43}$.

40 Tal y como comenta PONCE SOLÉ, el art. 70, referido al gobierno abierto, podría haber sido incluido perfectamente en sede de los preceptos referidos al buen gobierno y la buena administración, sobre todo, por su especial conexión con el art. 61 . Vid. "Bon govern, dret a una bona administració i prevenció de la corrupció", ob. cit., pág. 204. Pere Simón Castellano valora en términos de gobierno abierto positivamente este nuevo derecho del art. 70 LTAIPBGC; constituye una auténtica novedad, al regular el derecho de las personas que tienen reconocida la iniciativa legislativa popular a formular propuestas normativas de carácter reglamentario a la Administración competente, mas, la existencia real del mismo dependerá de cómo decida actuar la Administración, valorando las propuestas y aceptándolas o rechazándolas de forma motivada (atendiendo a su necesidad, los costes que conllevaría, su oportunidad y efectos que produciría), o dejando que se produzca simplemente la desestimación por silencio. Vid. "El govern obert", en Transparència, accés a la informació pública i bon govern a Catalunya: Comentaris sobre la Llei 19/2014, de 9 de desembre, ob. cit., págs. 227-229.

${ }^{41}$ De acuerdo con el art. 2 de la Ley 1/2006, de 16 de febrero, de la iniciativa legislativa popular, estarían legitimados para ejercerla, en primer lugar, las personas que tienen la condición política de catalanes, de acuerdo con el Estatuto de Autonomía de Cataluña, y no estén privadas de los derechos políticos y, además, las personas que no estén privadas de los derechos políticos, mayores de dieciséis años, debidamente inscritas como domiciliadas en el padrón de algún municipio de Cataluña y que cumplan uno de los siguientes requisitos: tener la nacionalidad española; ser ciudadanos de los Estados miembros de la Unión Europea salvo el Estado español o ciudadanos de Islandia, Liechtenstein, Noruega o Suiza; residir legalmente en España, de acuerdo con la normativa en materia de extranjería.

${ }^{42}$ En esta línea, el profesor José ESTEVE PARDO entiende que el Estado debe replegarse a posiciones en las que ya no se trata de desarrollar una actividad material directa para la cual no dispone ni de los medios ni de los conocimientos, «sino de garantizar que sus cometidos se realizan ahora adecuadamente, con los niveles de objetividad, accesibilidad y calidad exigibles, por los agentes privados que disponen de los medios», vid. "La Administración garante. Una aproximación”, RAP, núm. 197 (mayo-agosto 2015), págs. 11-39. https://doi.org/10.18042/cepc/rap.197.01. Asimismo, vid. José Luis CARRO FERNÁNDEZ-VALMAYOR, "Reflexiones sobre las transformaciones actuales del Derecho Público, en especial del Derecho Administrativo", RAP, núm. 193 (enero-abril 2014), págs. 11-44. En este contexto, comenta Eduardo GAMERO CASADO que «En la actual tesitura la Administración recibe mandatos contradictorios: por una parte se desea que su interferencia sea mínima, pero al mismo tiempo se le responsabiliza de cualquier fallo del sistema y se le atribuye una capacidad salvadora ilimitada. Por ejemplo, la necesidad de obtener una autorización para iniciar una actividad -apertura de una empresa, comercialización de un producto alimentario- se considera enojosa y contraria a la agilidad que merecen el empresario y el comercio; pero al mismo tiempo, si la empresa provoca perjuicios ambientales o el producto comercializado produce un daño a los consumidores, automáticamente se imputa a la Administración la responsabilidad de no haberlo evitado». Vid. Desafíos del Derecho Administrativo ante un mundo en disrupción, Comares, Granada, 2015, págs. 118-120.

${ }^{43}$ Así se han posicionado, entre otros, Garrido Falla, Leguina Villa, Martín Rebollo, Tornos Mas, Sánchez Morón, RodríguezArana y Tolosa Tribiño. Por ser un ferviente defensor de esta postura destacamos a Oriol MIR PUIGPELAT y algunos de sus trabajos, como: La responsabilidad patrimonial de la Administración. Hacia un nuevo sistema, Civitas, Madrid, 2001, "Responsabilidad objetiva 
Sin embargo, la Ley 40/2015, de 1 de octubre, de Régimen Jurídico del Sector Público (LRJSP), ha hecho oídos sordos y sigue manteniendo el carácter objetivo y directo de la responsabilidad patrimonial.

Tras la entrada en vigor de las Leyes 39 y 40/2015, existe una regulación legal dual de la responsabilidad patrimonial. En la primera, se contienen las normas procedimentales de la responsabilidad patrimonial como especialidades dentro del procedimiento administrativo común y, en la segunda, como legislación básica, los principios ${ }^{44}$.

Este hecho podría tener importantes consecuencias si tenemos en cuenta que hay Comunidades Autónomas que han proclamado que en materia de responsabilidad patrimonial existe una "competencia compartida» entre el Estado y la Comunidad Autónoma. Así, el art. 47.4 del Estatuto de Autonomía de Andalucía declara que «[C]orresponde a la Junta de Andalucía, en materia de responsabilidad patrimonial, la competencia compartida para determinar el procedimiento y establecer los supuestos que pueden originar responsabilidad con relación a las reclamaciones dirigidas a ellas, de acuerdo con el sistema general de responsabilidad de todas las Administraciones públicas». Y el art. 159.5 del Estatuto de Autonomía de Cataluña dice que «[C]orresponde a la Generalitat, en materia de responsabilidad, la competencia compartida para establecer las causas que pueden originar responsabilidad» ${ }^{45}$.

Con la nueva regulación de la responsabilidad patrimonial en dos normas, LPACAP y LRJSP, siguen quedando pendientes cuestiones centrales como cuándo responde la Administración por el funcionamiento normal de los servicios y cuándo surge la responsabilidad por el funcionamiento anormal ${ }^{46}$.

A la vista de la regulación actual de la responsabilidad patrimonial, cuyos principios se ubican en la Ley 40/2015, legislación básica, y del tenor del art. 159.5 del Estatuto de Autonomía de Cataluña, no sería impensable que pudiera tener cabida en el Título VI de la Ley 26/2010 la regulación de la técnica de los estándares de calidad como parámetro para determinar la anormalidad del funcionamiento y, en su caso, la antijuridicidad del daño producido y el derecho a ser indemnizado.

La técnica de los estándares de calidad, junto con otras como la doctrina de la lex artis ad hoc o la razonabilidad, son empleadas tanto por los jueces y tribunales ${ }^{47}$ como por los órganos consultivos de las

vs. funcionamiento anormal en la responsabilidad patrimonial de la Administración sanitaria”, REDA, 140 (2008), págs. 629-652 y "Propuestas para una reforma legislativa del sistema español de responsabilidad patrimonial de la Administración", en La responsabilidad patrimonial de las Administraciones Públicas. Crisis y propuestas para el s. XXI, Fundación Democracia y Gobierno Local, Madrid, 2009, págs. 33-60.

44 Estas Leyes suponen la disgregación en dos textos de la regulación de la responsabilidad patrimonial, obviando la opinión del Consejo de Estado, en sus dictámenes de 29 de abril de 2015 a los Anteproyectos de LPACAP y LRJSP, que apostaba por su regulación en una sola norma o en una ley especial ad hoc. En estos dictámenes destacaba el Consejo de Estado la necesidad de una «regulación íntegra y ordenada del régimen jurídico de la potestad sancionadora y la responsabilidad patrimonial de las Administraciones Públicas en su dimensión constitucionalmente garantizada, tal y como actualmente sucede con la Ley 30/1992; o, en el caso de que se mantenga el actual enfoque [que utiliza como criterio de delimitación de uno y otro anteproyecto las nociones de organización y procedimiento, a ninguna de las cuales se ajusta con exactitud la potestad sancionadora y la responsabilidad], se remita la disciplina de la potestad sancionadora y de la responsabilidad de las Administraciones Públicas a leyes singulares y distintas de los anteproyectos en cuestión».

45 Tal y como comenta el profesor LÓPEZ MENUDO, a pesar de la existencia de pronunciamientos del TC explicitando los títulos estatales sobre el «régimen jurídico de las Administraciones Públicas» y sobre el «procedimiento administrativo común» y su distinta intensidad, la desidia y falta de contundencia del legislador del 92 propició que pudieran dictarse leyes que proclaman que el procedimiento administrativo común o la responsabilidad patrimonial es una competencia compartida y la irrupción de las Comunidades Autónomas en un terrero, el de la responsabilidad, que en principio se consideraba tabú (arts. 47.2 y 4 del Estatuto de Autonomía de Andalucía y 159.5 del Estatuto de Autonomía de Cataluña). El hecho de que, siguiendo el criterio de lo que constituyen relaciones ad intra y ad extra, los principios de la responsabilidad patrimonial hayan sido regulados en la Ley 40/2015, constituye un hecho sorprendente a la par que grave, puesto que la competencia sobre el «sistema de responsabilidad de todas las Administraciones Públicas» es plena y exclusiva del Estado (art. 149.1.18. a CE). Vid. "Significación de los conceptos de procedimiento común y de régimen jurídico. Razones y sinrazones de la reforma”, en Innovaciones en el Procedimiento Administrativo Común y el Régimen Jurídico del Sector Público, ob. cit., págs. 31-32 y 37-38. La distribución de materias realizadas en las Leyes 39 y 40/2015, obliga, como afirma LÓPEZ MENUDO, a que "sólo desde la distancia», "solamente desde una perspectiva institucional que tenga en cuenta el ordenamiento entero y no únicamente la ocurrencia puntual del legislador de turno, puedan ser superados ciertos absurdos» y «pueda permitir rechazar de plano la idea de que las Comunidades autónomas puedan legislar a su aire sobre los principios de la potestad sancionadora o sobre el sistema de responsabilidad de las Administraciones Públicas», vid. el "Prólogo" a la obra dirigida por Eduardo GAMERO CASADO, Tratado de Procedimiento Administrativo Común y Régimen Jurídico básico del Sector Público, Tomo I, Tirant lo Blanch, Valencia, 2016 , pág. 58. En este contexto, veáse el análisis que en el citado Tratado realiza GAMERO CASADO de los títulos competenciales del Estado y su artículación en las Leyes 39 y 40/2015, “Encuadre de la nueva legislación en el acervo del Derecho Administrativo", ob. cit., págs. 105147 y, en especial, págs. 154-177.

46 En este sentido, vid. Tomás CANO CAMPOS, "La potestad sancionadora de la Administración: una regulación fragmentaria, incompleta y perniciosa", DA, núm. 2, 2015, nota a pie de página núm. 3.

47 Vid. sentencias del Juzgado Contencioso-administrativo de Barcelona de 20 de enero de 2015 (RJCA 2015।374), 30 de septiembre de 2015, FFJJ $3 .^{\circ}$ y 5..$^{\circ}$ (JUR 2016।228561), 13 de mayo de 2016, FJ 8..$^{\circ}$ (RJCA 2016l617), de 11 de julio de 2016 , FJ $4 .{ }^{\circ}$ (RJCA 
Administraciones ${ }^{48}$, convirtiendo de facto en numerosas ocasiones al sistema de responsabilidad patrimonial en un sistema culpabilístico.

La positivización de los estándares de calidad contenidos en las Cartas de Servicios (así como en otros instrumentos y normas) y su reconocimiento por el legislador ayudaría de forma notable a la hora de determinar la normalidad del funcionamiento del servicio y la no obligatoriedad de reparar el daño causado por parte de la Administración, sobre todo en supuestos de funcionamiento tardío o de inactividad ${ }^{49}$.

De esta forma, probablemente se evitarían o, al menos, se reducirían el número de resoluciones contradictorias que se dictan en supuestos similares, poniéndose coto al casuismo y minorando las grandes dosis de subjetivismo judicial de muchas sentencias ${ }^{50}$.

\section{Presunciones derivadas del cumplimiento de los estándares}

Partiendo de la necesidad de acometer un replanteamiento del alcance del sistema de responsabilidad patrimonial de las Administraciones Públicas españolas, de acuerdo con la normativa vigente entiendo que el incumplimiento de los estándares fijados por el legislador o por la Administración, bien sea en normas de hard law o de soft law, implica el surgimiento de una presunción iuris et de iure de que el funcionamiento del servicio público o la actuación de la Administración ha sido anormal y, por ende, que el daño que se haya causado tenga que ser indemnizado por ser antijurídico (siempre que se cumplan el resto de requisitos legalmente exigibles). En consecuencia, cuando del incumplimiento de los compromisos y estándares de calidad fijados en las Cartas de Servicios dictadas al amparo de la LTAIPBGC se generasen daños en el particular, al tratarse de normas de carácter reglamentario, surgiría iuris et de iure la responsabilidad de la Administración catalana correspondiente.

Por otra parte, el cumplimiento de dichos estándares se identificaría con una presunción iuris tantum de que la actuación administrativa ha sido normal. En consecuencia, habría que estar a las circunstancias del caso concreto, a los daños sufridos y al análisis del nivel de exigencia o calidad en la prestación del servicio fijado en el instrumento normativo correspondiente.

Con el fin de dotar al sistema de mayor seguridad jurídica y a los jueces de un parámetro objetivo de cuál sea el nivel de calidad adecuado en cada contexto, es aconsejable que aquéllos puedan contar con el criterio de expertos u órganos especializados y con acreditada solvencia que certifiquen de forma imparcial y transparente el nivel correspondiente al estándar objeto de debate. En este sentido, conviene apostar por la creación de órganos externos que acrediten los niveles reales de calidad de cada servicio y su idoneidad, y que esa declaración formal, independiente, de si se cumplen o no determinados requisitos, sirva como prueba cualificada para demostrar el nivel de calidad con el que efectivamente se presta el mismo por parte de la Administración. El órgano judicial dispondría así de un valioso medio de prueba para, en situaciones de un funcionamiento normal del servicio, considerar o no antijurídico el daño producido en función del nivel de calidad acreditado y de la exigencia o no a la Administración de otro tipo de comportamiento en el caso en cuestión.

Desde esta perspectiva, el concepto de antijuridicidad debiera exonerar aquellos daños que se encuentren justificados por el ordenamiento jurídico y que, presumiblemente, serían aquellos generados a raíz de un funcionamiento normal del servicio en el que se hubiesen respetado todos los estándares de calidad

20161883) y 22 de septiembre de 2016, FFJJ $10^{\circ}$ y $9 .^{\circ}$ (JUR 20161252313); sentencia del Juzgado de lo Contencioso-administrativo núm. 1 de Lérida de 20 de julio de 2016, FJ 6. (JUR 20161201762); y SSTSJ de Cataluña de 22 de diciembre de 2015, FJ 6..$^{\circ}$ (JUR 2016l13958) y de 22 de marzo de 2016, FJ 5. (JUR 2016।138380).

48 Vid. dictámenes de la Comissió Juridica Assessora de la Generalidad de Cataluña 408/2014, de 27 de noviembre y 440/2014 y 441/2014, ambos de 17 de diciembre.

49 Esta interpretación, aludiendo expresamente a los estándares contenidos en las Cartas de Servicios, es la que mantiene el Tribunal Superior de Justicia de Cataluña en el fundamento jurídico $5 .^{\circ}$ de su sentencia núm. $379 / 2017$, de 30 de mayo, relativa a una reclamación de responsabilidad patrimonial contra el Departamento de Interior de la Generalidad de Cataluña por la deficiente prestación del servicio de prevención de incendios, cuya tardanza en acudir a la vivienda en la que se había producido un incendio -excediendo el tiempo de desplazamiento de lo que sería un estándar normal y aceptable-, supuso la pérdida de oportunidad de salvar la vida de un menor que se encontraba en ella.

50 En este sentido se expresa Juli PONCE SOLÉ cuando manifiesta que «el establecimiento de estándares claros de buena administración [en las Cartas de Servicios] permitiría conocer cuando se produce una mala administración (o funcionamiento anormal de la Administración) y por tanto substituir la discrecionalidad judicial en la apreciación de ésta como elemento para condenar a la Administración, lo que ocurre en ciertos sectores de la actividad administrativa, como el sanitario, y en relación a la actividad administrativa formalizada ilegal, como es sabido», vid. "La discrecionalidad no puede ser arbitrariedad y debe ser buena administración”, ob. cit., pág. 74. 
establecidos y que además estuvieran valorados y/o acreditados como de un nivel adecuado, suficiente o, incluso, alto u óptimo, sin que éste último equivalga a un grado de exigencia en el desarrollo del servicio inasumible e irrazonable desde un punto de vista realista y lógico ${ }^{51}$.

En cualquier caso, el cumplimiento de las normas de calidad establecidas, incluso de un nivel elevado, no puede conllevar ipso iure la exoneración de la responsabilidad de la Administración, dado que pueden plantearse situaciones que, aunque más cercanas al régimen expropiatorio, mientras no se acometa una reforma legislativa en dicho ámbito, hayan de atenderse en sede de responsabilidad y, en función de las circunstancias del caso concreto, la Administración causante del daño deba responder e indemnizar ante el particular, pudiendo en tales supuestos tener el cumplimiento de los estándares de calidad establecidos una posible repercusión a la hora de determinar la cuantía indemnizatoria.

\section{CONCLUSIONES}

De acuerdo con la normativa estatal y autonómica (salvo en Cataluña), el cumplimiento de los compromisos de calidad no es vinculante para el ente administrativo, lo cual merma la fuerza de este instrumento, provocando a su vez en el ciudadano la incomprensible situación de que el incumplimiento por parte de la Administración de lo por ella acordado y publicado no tiene consecuencias jurídicas. Es por ello, que mi postura es clara: las Cartas de Servicios deberían ser incorporadas al ordenamiento jurídico, transformando su rasgo de cumplimiento voluntario por el de obligatorio, como ha hecho la Ley 19/2014.

Del análisis realizado sobre la implantación de las Cartas de Servicios de forma obligatoria y con carácter reglamentario y efectos vinculantes en Cataluña a partir de la entrada en vigor de la Ley 19/2014 se concluye que, en estos momentos, el número de Cartas de Servicios aprobadas es limitado.

Una parte de las Cartas de Servicios aprobadas antes de la Ley 19/2014, tras haber sido revisadas en 2015, 2016 o 2017, no contemplan ni se ajustan al nuevo diseño y planteamiento que de estos instrumentos hace aquélla.

De las elaboradas y publicadas en 2016 y 2017, la mayoría no respeta el contenido mínimo obligatorio que exige el art. 59 LTAIPBGC o no reconoce la naturaleza normativa de la Carta de Servicios. No se aprecia en ellas un giro en su planteamiento respecto a las consecuencias que derivan del incumplimiento de los estándares de calidad fijados en sus compromisos, los cuales, en algunos casos, precisan de ser concretados correctamente y puestos en relación con sus correspondientes indicadores, evitando la ambigüedad o ser mera reproducción de obligaciones y plazos ya establecidos legalmente.

La realidad es, como manifiesta el Síndic de Greuges en sus informes, que sólo un bajísimo número de las Cartas de Servicios aprobadas cumple con los presupuestos de la Ley 19/2014.

Vistos los distintos procedimientos de elaboración que se están siguiendo para aprobar las Cartas, cómo se está abordando la redacción de sus contenidos y, más especialmente, de los estándares de calidad y sus indicadores, se hace más que conveniente, necesario, el que la Administración de la Generalidad cuente con una Guía de Elaboración de sus Cartas de Servicios y ofrezca un modelo-tipo que puedan seguir tanto sus órganos y entes instrumentales, como las entidades locales de esta Comunidad. De esta forma, se proporcionaría mayor seguridad jurídica respecto al procedimiento a seguir para su elaboración y aprobación y sobre su contenido, así como sobre las consecuencias de su incumplimiento.

En suma, la regulación que hace el ordenamiento jurídico catalán de las Cartas de Servicios es innovadora, por ahora, única, pero ha de ser puesta en práctica de conformidad con lo que establecen la Ley 19/2014 y la Ley 26/2010. Se ha dado un paso importante en la dirección que marca el principio de la buena administración, esperemos que el buen gobierno acompañe y haga realidad con su impulso y gestión que se elaboren Cartas de Servicios que verdaderamente contemplen y garanticen servicios públicos de calidad.

\section{BIBLIOGRAFÍA}

ANTELO MARTíNEZ, A. R. (2016), "Elaboración de disposiciones de carácter general en la Administración Local, tras la entrada en vigor de la Ley 39/2015", Revista de Estudios de la Administración Local y Autonómica, 6: 105-121.

51 Como dice Ricardo DE VICENTE DOMINGO, «[N]o se exige a la Administración una actuación perfecta propia de estándares de conducta irrazonables o exorbitantes (...)», vid. "Discrecionalidad e inactividad. El principio de actuación suficiente", ob. cit., pág. 18. 
CANO CAMPOS,T. (2015), "La potestad sancionadora de la Administración: una regulación fragmentaria, incompleta y perniciosa", Documentación Administrativa, 2: 1-5.

- (2016), "Derechos y deberes de las personas en sus relaciones con las Administraciones Públicas: la vuelta del «administrado», en Innovaciones en el Procedimiento Administrativo Común y el Régimen Jurídico del Sector Público: 122-146, Sevilla, EUS.

CARRO FERNÁNDEZ-VALMAYOR, J. L. (2014), "Reflexiones sobre las transformaciones actuales del Derecho Público, en especial del Derecho Administrativo", Revista de Administración Pública, 193: 11-44.

DE VICENTE DOMINGO, R. (2014), "Discrecionalidad e inactividad. El principio de actuación suficiente”, Revista Española de Derecho Administrativo, 165: 71-102.

ESTEVE PARDO, J. (2015), “La Administración garante. Una aproximación”, Revista de Administración Pública, 197: 11-39.

FERREIRO SEOANE, F. J. (2016), "La RPT como un instrumento de organización de las administraciones locales", Revista de Estudios de la Administración Local y Autonómica, 5: 1-25.

FUENTETAJA PASTOR, J. Á. (2008), "El derecho a la buena administración en la Carta de los Derechos Fundamentales de la Unión Europea”, Revista de Derecho de la Unión Europea, 15: 137-154.

GAMERO CASADO, E. (2015), Desafíos del Derecho Administrativo ante un mundo en disrupción, Granada, Comares.

- (2017), "Encuadre de la nueva legislación en el acervo del Derecho Administrativo", en Tratado de Procedimiento Administrativo Común y Régimen Jurídico básico del Sector Público: 57-104, Tomo I, Valencia, Tirant lo Blanch.

GUILLEM CARRAU, J. (2010), "El avance del derecho a la buena administración en el Tratado de Lisboa”, Revista de Derecho de la Unión Europea, 19: 31-70.

LÓPEZ MENUDO, F. (2016), "Significación de los conceptos de procedimiento común y de régimen jurídico. Razones y sinrazones de la reforma", en Innovaciones en el Procedimiento Administrativo Común y el Régimen Jurídico del Sector Público: 13-39, Sevilla, EUS.

- (2017), "Prólogo" a la obra dirigida por Eduardo Gamero Casado, Tratado de Procedimiento Administrativo Común y Régimen Jurídico básico del Sector Público: 5-12, Tomo I, Valencia, Tirant lo Blanch.

MARTÍN DELGADO, I. (2016), "La reforma de la Administración Electrónica: una panorámica general del impacto de la nueva Ley de Procedimiento Administrativo Común en las relaciones de los ciudadanos con la Administración Pública", en Innovaciones en el Procedimiento Administrativo Común y el Régimen Jurídico del Sector Público: 41-82, Sevilla, EUS.

MARTÍNEZ LÓPEZ-MUÑIZ, J. L. (2016), "La elaboración de los reglamentos", en Innovaciones en el Procedimiento Administrativo Común y el Régimen Jurídico del Sector Público: 307-344, Sevilla, EUS.

MIR PUIGPELAT, O. (2001), La responsabilidad patrimonial de la Administración. Hacia un nuevo sistema, Madrid, Civitas.

- (2008), "Responsabilidad objetiva vs. funcionamiento anormal en la responsabilidad patrimonial de la Administración sanitaria", Revista Española de Derecho Administrativo, 140: 629-652.

- (2009) "Propuestas para una reforma legislativa del sistema español de responsabilidad patrimonial de la Administración", en La responsabilidad patrimonial de las Administraciones Públicas. Crisis y propuestas para el s. XXI: 33-60. Madrid, Fundación Democracia y Gobierno Local.

PONCE SOLÉ, J. (2015), "Bon govern, dret a una bona administració i prevenció de la corrupció", en Transparència, accés a la informació pública i bon govern a Catalunya: Comentaris sobre la Llei 19/2014, de 9 de desembre: 177218, Barcelona, UOC.

- (2016), "La discrecionalidad no puede ser arbitrariedad y debe ser buena administración", Revista Española de Derecho Administrativo, 175: 57-84.

- (2017), "Los jueces, el derecho a una buena administración y las leyes de transparencia y buen gobierno", [19-012017], publicado en http://laadministracionaldia.inap.es/noticia. asp?id=1507021.

- (2017a), "Introducción", Innovación en el ámbito del buen gobierno regulatorio: ciencias del comportamiento, transparencia y prevención de la corrupción, codirigida con Agustí Cerrillo i Martínez, Madrid, INAP.

SIMÓN CASTELLANO, P. (2015), "El govern obert", en Transparència, accés a la informació pública i bon govern a Catalunya: Comentaris sobre la Llei 19/2014, de 9 de desembre: 219-233, Barcelona, UOC. 